\title{
Influence of biological factors on injuries occurrence in the Polish population
}

\author{
Marta Stępień-Słodkowska', Krzysztof Ficek², Mariusz Kaczmarczyk³ \\ Agnieszka Maciejewska', Marek Sawczuk' ${ }^{1}$, Jerzy Eider ${ }^{1}$, Marian Sygit ${ }^{1,4}$, \\ Agata Leońska-Duniec ${ }^{1,5}$, Paweł Ziętek ${ }^{6}$, Katarzyna Sygit ${ }^{1}$, Paweł Cieszczyk ${ }^{1,5}$ \\ ${ }^{1}$ Faculty of Physical Education and Health Promotion, University of Szczecin, Poland \\ ${ }^{2}$ Academy School of Physical Education in Katowice, Poland \\ ${ }^{3}$ Department of Clinical and Molecular Biochemistry, Pomeranian Medical University of Szczecin, Poland \\ ${ }^{4}$ Institute of Rural Health in Lublin, Poland \\ ${ }^{5}$ Department of Sport Education, Academy of Physical Education and Sport, Gdansk, Poland \\ ${ }^{6}$ Department of Orthopaedics, Traumatology and Oncology, Pomeranian Medical University of Szczecin, Poland
}

Stępień-Słodkowska M, Ficek K, Kaczmarczyk M, Maciejewska A, Sawczuk M, Eider J, Sygit M, Leońska-Duniec A, Ziętek P, Sygit K, Cieszczyk P. Influence of biological factors on injuries occurrence in the Polish population. Ann Agric Environ Med. $2016 ; 23(2)$ : 315-318. doi: $10.5604 / 12321966.1203897$

\section{Abstract}

Introduction and objective. Anterior cruciate ligament rupture is one of the most common knee injuries in sports. Although various intrinsic and extrinsic risk factors have been identified, the exact aetiology of the injury is not yet fully understood. Single nucleotide polymorphisms (SNPs) in the collagen type I (COL1A1) gene have been shown to be associated with several complex connective tissue disorders. The aim of this study was to examine the association of -1997G/T polymorphisms in the COL1A1 gene with ACL ruptures in Polish recreational skiers in a case-control study.

Materials and methods. A total of 180 male and female recreational skiers with surgically diagnosed with primary ACL ruptures were recruited for the study, all of whom qualified for ligament reconstruction. The control group was comprised of 245 apparently healthy male and female skiers with a comparable level of exposure to ACL injury, none of whom had any self-reported history of ligament or tendon injury. DNA samples extracted from the oral epithelial cells were genotyped for $-1997 \mathrm{G} / \mathrm{T}$ polymorphisms using PCR method.

Results. Genotype distribution in the cases (GG-82.2\% GT-16.7\%; TT-1.1\%) showed significant difference $(P=0.036)$ compared to controls (GG-71.4\% GT-26.5\%; TT-2.2\%). The frequency of the GG genotype in the ACL rupture group was also statistically significant ( $p=0.011$, Fisher's exact test recessive mode: GG vs GT+TT). The frequency of the $\mathrm{G}$ allele was higher in these cases $(90.6 \%)$, and also statistically significant $(p=0.012)$ when compared with controls $(84.7 \%)$.

Conclusion. The results obtained indicate that the -1997G/T COL1A1 gene is one of the genetic markers to be taken into the consideration in the identification of the risk of ACL injury.

\section{Key words}

anterior cruciate ligament $(A C L)$ rupture, COL1A1 gene, collagen, polymorphism

\section{INTRODUCTION}

The knee is the largest and most complex joint in the human body. Its stability is largely dependent on the ability of the anterior cruciate ligament (ACL) to resist anterior tibial translational loads and rotational loads $[1,2]$. The ACL is composed of dense fibrous connective tissue that attaches the femur to the tibia. It has a large amount of collagen fibres arranged in a hierarchal pattern which give it high tensile strength [1]. Collagen is the main component of ligaments [3]. Collagen type I is a heterotrimer consisting of two alpha 1 chains and one alpha 2 chain [4]. It accounts for $85 \%$ of all collagen and the rest is made up of types III, VI, V, XI and XIV, which account for approximately $75 \%$ of the dry weight, with the balance being made up of proteoglycans, elastin and other proteins and glycoproteins, such as actin, laminin and the integrins [5]. A failure of lower extremity muscle control during provocative activities, such as jumping, cutting and pivoting, can increase demand on the static joint stabilizers and lead to ACL rupture [6].

Address for correspondence: Marta Stępień-Słodkowska, University of Szczecin Piastów 40B, 71-065 Szczecin, Poland

E-mail: marta.slodkowska1@wp.pl

Received: 03 November 2013; accepted: 30 April 2014
Anterior cruciate ligament rupture is one of the most common knee injuries in sports [7]. The tendon injuries account for approximately $30-50 \%$ of all sporting injuries [8]. ACL injury has a devastating influence on individual activity levels and quality of life. Complete ACL rupture can induce other pathological knee conditions, including knee instability, damage to menisci and the chondral surface, and osteoarthritis. It is estimated that approximately 175,000 primary ACL reconstruction surgeries were performed annually in the USA with an estimated cost of over $\$ 2$ billion (USD) [9]. Ligament rupture occurs as internal forces exceed ligament tensile properties. Rupture of the ACL changes the kinematics of the knee, and often results in instability with accompanying functional disability and pain [10]. Injury of the ACL not only causes mechanical instability, but also leads to a functional deficit in the form of diminished proprioception of the knee joint [2]. ACL tears will not heal without surgical intervention due to low blood supply and ligament retraction from the synovial tissue that envelops a tear [1].

Despite the fact that skiing is one of the few sports where the height and weight of each individual are taken into consideration when assigning equipment, skiers are also one of the groups of athletes with the highest frequency of ACL rupture [11]. ACL injuries represent $17.2 \%$ of all ski injuries [12]. 
The majority of research into non-contact ACL injury risk factors and the accompanying gender disparity has focused on the neuromuscular and biomechanical risk factors because of their potential for modification [13]. Neuromuscular training strategies focusing on warm-up, technique, balance, strengthening and agility exercises have continued to evolve and represent an ever-increasing and important research focus. The epidemiological data, however, suggest that in spite of these ongoing initiatives and reported early successes, ACL injury rates and the associated gender disparity have not diminished. A return to high activity level after a unilateral ACL injury is the most important risk factor of sustaining a contralateral ACL injury [14].

Although various intrinsic and extrinsic risk factors have been identified, the exact aetiology of the injury is not yet fully understood. Single nucleotide polymorphisms (SNPs) in the collagen type I (COL1A1) gene have been shown to be associated with several complex connective tissue disorders [3]. The COL1A1 gene is located on chromosome 17q21 and contains 51 exons $[15,16]$. The $\mathrm{G}$ to $\mathrm{T}$ substitution in an intronic Sp1 binding site (rs1107946), resulting in increased affinity for the transcription factor $\mathrm{Spl}$ and increased gene expression, has been one of the most extensively investigated polymorphisms within this gene. COL1A1 has been shown to be associated with an increased risk of shoulder dislocations, Achilles tendon ruptures and Achilles tendinopathy [17].

Studies have also shown an association of another polymorphism with the risk of ACL rupture [18]. The authors found that a rare TT genotype of the Spl polymorphism was significantly under-represented among participants with ACL ruptures. It was theorized that a variant allele $\mathrm{T}$ of the Sp1 binding site polymorphism enhances the binding of the transcription factor Sp1, thereby increasing COL1A1 expression and the production rate of alpha-1 chains, resulting in the production of homotrimers alpha-1.

In the present state of knowledge, any genes which encode these proteins that are functionally associated with ligaments could be potential candidates. Therefore, any such genes and proteins which have already been implicated with ACL injury should be designated as candidates of priority. In light of the facts, it was decided to investigate whether COL1A1 -1997 G/T polymorphism was associated with ACL ruptures in Polish recreational skiers.

\section{OBJECTIVE}

The aim of the study was to examine the association of -1997 G/T polymorphisms in the COL1A1 gene with ACL ruptures in Polish recreational skiers in a case-control study.

\section{MATERIALS AND METHOD}

A total of 180 male $(n=142)$ and female $(n=38)$ recreational skiers $(27 \pm 2)$ with surgically diagnosed primary ACL ruptures were recruited for the study, all of whom qualified for ligament reconstruction. The control group was comprised of 245 apparently healthy male $(n=183)$ and female $(n=62)$ skiers $(24 \pm 6)$ with a comparable level of exposure to ACL injury, none of whom had any self-reported history of ligament or tendon injury. The control group consisted of subjects who were all of the same ethnicity, similar in age, participating in the same sport, their knee joints being exposed to comparable forces and movements, in order to control the many internal and external risk factors.

The Pomeranian Medical University Ethics Committee approved the study and written informed consent was obtained from each participant. The study complied with the guidelines set out in the ethics policy of the university of Szczecin [19].

Determination of COL1A1 genotypes. Genomic DNA was extracted from the oral epithelial cells using GenElute Mammalian Genomic DNA Miniprep Kit (Sigma, Germany), according to the manufacturer's protocol. Allelic discrimination of COL1A1 -1997G/T (rs1107946) polymorphic site was performed using TaqMan PreDesigned SNP Genotyping Assays (Applied Biosystems, USA), including primers and fluorescently labelled (FAM and VIC) MGB probes for the detection of alleles. All samples were genotyped on StepOne Real-Time Polymerase Chain Reaction (PCR) instrument (Applied Biosystems, USA). Thermal cycler conditions were as follows: an initial step at $95^{\circ} \mathrm{C}$ for $5 \mathrm{~min}$, followed by 45 cycles of denaturation at $94^{\circ} \mathrm{C}$ for $15 \mathrm{~s}$ and anneal/extend at $60^{\circ} \mathrm{C}$ for $1 \mathrm{~min}$. All genetic analyses were performed in the Sports Genetic Research Centre at the Academy of Physical Education and Sport in Gdańsk, Poland.

Statistical analysis. Differences in the genotypes and allele ( $G$ and $T$ ) frequency were analyzed using $\chi^{2}$ or Fisher exact tests. A general test of association in the 2-by-3 table of phenotype-by-genotype was performed. Then two different modes of inheritance of the minor allele were assumed: dominant, in which homozygotes and heterozygotes for the minor allele were pooled and compared to homozygotes for the major allele, and recessive, in which homozygotes for the minor allele were compared with pooled homozygotes and heterozygotes for the major alleles. $P$ values $\mathrm{p}<0.05$ were considered statistically significant.

\section{RESULTS}

Genotype distributions among cases and controls were in Hardy-Weinberg equilibrium, making selection bias less likely. Genotypes and alleles distribution are given in Table 1. Genotype distribution in the cases (GG-82.2\% GT-16.7\%; TT-1.1\%) showed significant difference $(\mathrm{P}=0.036)$ compared to controls (GG-71.4\% GT-26.5\%; TT-2.2\%).

The frequency of the GG genotype in the ACL rupture group was also statistically significant ( $\mathrm{p}=0.011$, Fisher's exact test recessive mode: GG vs GT+TT). The frequency of the G

Table 1. Association between -1997G/T (Sp1, rs1107946) in COL1A1 and ACL ruptures

\begin{tabular}{|c|c|c|c|c|c|c|c|c|}
\hline \multirow{2}{*}{ Group } & \multirow{2}{*}{$N$} & \multicolumn{3}{|c|}{ COL1A1genotype } & \multirow{2}{*}{$P^{*}$} & \multicolumn{2}{|c|}{ COL1A1 allele } & \multirow{2}{*}{$P$} \\
\hline & & GG & GT & $\mathrm{TT}$ & & G & $\mathrm{T}$ & \\
\hline $\begin{array}{l}\text { InjuredACL } \\
\text { skiers }\end{array}$ & 180 & $\begin{array}{c}148 \\
(82.2)\end{array}$ & $\begin{array}{c}30 \\
(16.7)\end{array}$ & $\begin{array}{c}2 \\
(1.1)\end{array}$ & \multirow{2}{*}{$\begin{array}{l}0.036 \\
0.704^{1} \\
0.011^{2}\end{array}$} & $\begin{array}{c}326 \\
(90.6)\end{array}$ & $\begin{array}{c}34 \\
(9.4)\end{array}$ & \multirow{2}{*}{0.012} \\
\hline Control & 245 & $\begin{array}{c}175 \\
(71.4)\end{array}$ & $\begin{array}{c}65 \\
(26.5)\end{array}$ & $5(2.0)$ & & $\begin{array}{c}415 \\
(84.7)\end{array}$ & $\begin{array}{c}75 \\
(15.3)\end{array}$ & \\
\hline
\end{tabular}

${ }^{1} \mathrm{TT}$ vs. GG+GT; ${ }^{2} \mathrm{GG}$ vs. GT+TT

Data is given as $\mathrm{n}$-values with percentages in parentheses 
allele was higher in the cases $(90.6 \%)$, and also statistically significant $(\mathrm{p}=0.012)$ when compared with controls $(84.7 \%)$.

\section{DISCUSSION}

The results indicate a higher frequency of the COL1A1 G allele and GG genotype in patients with ACL injury. These results suggest that the $-1997 \mathrm{G} / \mathrm{T} C O L 1 \mathrm{~A} 1$ gene is one of the genetic markers to be taken into the consideration in the identification of the risk of ACL injury.

Although the sequences of the 3.2 billion bases of human DNA are over $99.9 \%$ identical, the sequence variations (polymorphisms) in human DNA contribute to the visible and measurable biological variation observed in individuals [17]. Genetic association studies still remain one of the more common methods used to identify specific regions of the genome that contain genes that predispose individuals to an increased risk of disease [20]. Many of the common intrinsic risk factors implicated in injuries include: previous injury, somatotype, neuromuscular characteristics, biomechanical features, anatomical features and flexibility/laxity. These, together with several other non-genetic factors are, to a lesser or greater extent, determined by genetic factors [17]. Athletes with intrinsic risk factors for acute injuries, which include a genetic component, become injured after exposure to extrinsic factors and an inciting event [21].

A familial predisposition to ACL rupture, welldocumented in a few studies, would suggest that there is a genetic component to this knee injury and possibly to other musculoskeletal soft tissue injuries [18, 22]. Studies have also suggested that there is, at least in part, a genetic component to Achilles tendon and rotator cuff injuries [8]. Pre-screened mature female twins who subsequently experienced ACL injury demonstrated multiple potential risk factors, including: increased knee abduction angles, decreased knee flexion angles, increased general joint laxity, decreased H/Q (hamstring to quadriceps peak torque) ratios and femoral intercondylar notch width [22]. Genetic makeup should be considered as an intrinsic risk factor for ACL rupture. It was previously shown that individuals who had a family history of ACL rupture exhibited 2-fold higher risk for ACL rupture [23].

Therefore, genetic research plays a justifiably large role in sport, one which increases with every passing year. Knowledge of the role of individual genes in the processes occurring in the human body can also be used in sport rehabilitation and injury prevention. Precise determination of genotypes at risk for acute or chronic diseases related to sport will probably allow changes in individual training plans to greatly minimize the risk of injury [24].

Changes in the collagen, proteoglycan, and glycoprotein content and composition, as well as the expression of many of the genes that encode for these proteins, have been shown to be altered in ligament injuries [17]. The COL1A1 and $C O L 5 A 1$ genes encode for the major a chains that make up these collagens, and sequence variant horns within these genes are potential intrinsic risk factors for ACL ruptures [8]. A common C/T (allele C, allele T) single nucleotide polymorphism - SNP rs12722 (BstUI RFLP) in the 3'-untranslated region (3'-UTR) of COL5A1 was shown to be associated with chronic Achilles tendinopathy [20, 25] and with anterior cruciate ligament injuries in females [26].
In all these studies, the CC genotype was shown to be overrepresented in the respective asymptomatic controls [27].

The gene encoding matrix metalloproteinase-3 (MMP-3, stromelysin-1) was shown to be associated with anterior cruciate ligament ruptures. The $5 \mathrm{~A} / 6 \mathrm{~A}$ polymorphism in the promoter of the MMP-3 gene affects the regulation of MMP-3 gene expression. Statistical analyses of genotype frequencies between patients and healthy controls were performed by the chi-square test [28]. A significant difference was found between ACL rupture subgroups in terms of genotype association $(5 \mathrm{~A}+(5 \mathrm{~A} / 5 \mathrm{~A}, 5 \mathrm{~A} / 6 \mathrm{~A}): 37.5 \%$ in contact sports vs. $20 \%$ in non-contact sports; $\mathrm{P}=0.02)$. In allelic association, there were significant differences (6A: $81.2 \%$ in contact sports vs. $89.1 \%$ in non-contact sports, $5 \mathrm{~A}: 18.8 \%$ in contact sports vs. $10.9 \%$ in non-contact sports, $\mathrm{P}=0.01$ ). The $5 \mathrm{~A}+$ genotype of MMP-3 was represented in ACL ruptures in contact sport participants [29].

Similar research results were obtained in studies conducted among patients with cruciate ligament rupture and shoulder dislocation. Compared with the homozygous SS category, the heterozygous participants displayed a similar risk (OR, 1.06; 95\% CI, 0.76-1.49), whereas the ss genotype was underrepresented in the injured population compared with the controls (OR, 0.15; 95\% CI, 0.03-0.68). This latter estimate was similar for both cruciate ligament ruptures and shoulder dislocations, and was furthermore not modified by general joint laxity. Varying levels of risk of these injuries was found in association with collagen type I alpha1 Spl polymorphisms [30].

Other studies have suggested that the rare TT genotype of functional Sp1 binding site polymorphism within intron 1 of COL1A1 is associated with infrequency of cruciate ligament ruptures (CL), shoulder dislocation (SD) and Achilles tendon ruptures. A study by Collins et al. showed that similar genotype distributions were reported for the control and injury groups in all three studies [31]. The TT genotype, when compared to the control group (4.1\%, $\mathrm{n}=24$ of 581), was significantly under-represented in the (1) CL $(0.3 \% ; n=1$ of $350 ; \mathrm{OR}=15.0 ; \mathrm{P}=0.0002)$, (2) $\mathrm{CL}$ and $\mathrm{SD}(0.4 \%$ TT genotype; $\mathrm{n}=2$ of $476 ; \mathrm{OR}=10.2 ; \mathrm{P}<0.0001)$, and (3) CL, SD and Achilles tendon ruptures $(0.4 \%$ TT genotype; $n=2$ of 517 ; $O R=11.1$; $\mathrm{P}<0.0001)$ groups. This combined analysis indicates that the TT genotype appears to be protected against acute soft tissue ruptures and should be incorporated into multifactorial models determining risk for acute soft tissue ruptures.

The presented study examined the association between the collagen type I alpha 1gene - COL1A1 single nucleotide polymorphism -1997G/T (Sp1, rs1107946) and ACL ruptures in Polish skiers. The results obtained were consistent with the hypothesis that the T1997G COL1A1 polymorphism is associated with ACL injury. Statistical difference was found in the T1997G genotype and allele frequencies in the skiers group with surgically confirmed primary ACL ruptures, compared to the control group.

In the current study, male and female skiers with surgically confirmed primary ACL rupture, who were qualified for an ACL reconstruction procedure were investigated. It seems that males participating in sport may be at greater risk for injury than females as they tend to be more aggressive, have a larger body mass, and experience greater contact compared with women in the same sports.

Tendon and ligament injuries are complex, multifactorial conditions, caused by interactions of a number of 
different proteins, encoded by different genes on different chromosomes, and the interactions of these genetic components with different environmental factors [32]. Therefore, genetic association studies must always be interpreted with caution. The presented findings should be supported with more experimental studies on COL1A1 polymorphisms, including their interaction with other genes. Additionally, the results need to be confirmed in a larger sample of subjects.

\section{CONCLUSIONS}

The results obtained indicate a higher frequency of the COL1A1 $\mathrm{G}$ allele and GG genotype in patients with ACL injury. The results also suggest that the $-1997 \mathrm{G} / \mathrm{T}$ COL1A1 gene is one of the genetic markers to be taken into the consideration in the identification of the risk of ACL injury. However, these conclusions should be supported with further investigation, including evaluation of Type I / Type III collagen ratio, and the possible effect of microRNAs, to explain the relationship between COL1A1 expression and susceptibility to ACL injury.

\section{REFERENCES}

1. Tovar N, Bourke S, Jaffe M, Murthy NS, Kohn J, Gatt C, Dunn MGA. Comparison of degradable synthetic polymer fibers for anterior cruciate ligament reconstruction. J Biomed Mater Res A. 2010; 93(2): 738-747.

2. Dhillon MS, Bali K, Prabhakar S. Proprioception in anterior cruciate ligament deficient knees and its relevance in anterior cruciate ligament reconstruction Indian. J Orthop. 2011; 45(4): 294-300.

3. O'Connell K, Saunders CJ, Collins M. Collagen gene sequence variants in exercise-related traits. Cent Eur J Sport Sci Med. 2013; 1(1): 3-17.

4. Amor MB, Glorieux FH, Rauch F. Genotype-phenotype correlations in autosomal dominant osteogenesis imperfecta. J Osteoporos. 2011: 540178.

5. Frank CB. Ligament structure, physiology and function. J Musculoskel Neuron Interact. 2004; 4(2): 199-201.

6. Hurd WJ, Axe M, Snyder-Mackler L, Influence of age, gender, and injury mechanism on the development of dynamic knee stability after acute ACL rupture. J Orthop Sports Phys Ther. 2008; 38(2): 36-41.

7. Legnani C, Terzaghi C, Borgo E, Ventura A. Management of anterior cruciate ligament rupture in patients aged 40 years and older. J Orthop Traumatol. 2011; 12(4): 177-184.

8. September AV, Schwellnus MP, Collins M. Tendon and ligament injuries: the genetic component. Br J Sports Med. 2007; 41(4): 241-246.

9. Yu B, Garrett WE. Mechanisms of non-contact ACL injuries. Br J Sports Med. 2007; 41(1): 47-51.

10. Farshad M, Gerber C, Meyer DC, Schwab A, Blank PR, Szucs T. Reconstruction versus conservative treatment after rupture of the anterior cruciate ligament: cost effectiveness analysis. Health Serv Res. 2011; 11: 317.

11. Habelt S, Hasler CC, Steinbrück K, Majewski M. Sport injuries in adolescents. Orthop Rev (Pavia) 2011; 3(2): 18.
12. Kim S, Endres NK, Johnson RJ, Ettlinger CF, Shealy JE. Snowboarding injuries: trends over time and comparisons with alpine skiing injuries. Am J Sports Med. 2012; 40(4): 770-6.

13. Benjaminse A, Lemmink K, Diercks RL, Otten B. An investigation of motor learning during side-step cutting, design of a randomised controlled trial. Musculoskelet Disord. 2010; 11: 235.

14. Swärd P, Kostogiannis I, Roos H. Risk factors for a contralateral anterior cruciate ligament injury. Knee Surg Sports Traumatol Arthrosc. 2010; 18 (3): 277-91.

15. Zhang D, Shi Y, Gong B, He F, Lu F, Lin H, Wu Z, Cheng J, Chen B, Liao S, Ma S, Hu J, Yang Z. An association study of the COL1A1 gene and high myopia in a Han Chinese population. Epub. 2011; 17: 3379-83.

16. Meyer, Haist, Schaefer, Ivan, Ittner, Nawroth, Plöckinger, Stalla, Tuschy, Weber, Weise A, Pfützner, Habbe N. Kann PH. Association of COLIA1 Sp1 polymorphism with the effect of subcutaneously injected recombinant hGH in GH-deficient adults Pharmacogenomics. 2008; 9(8): 1017-1026

17. Collins M, Raleigh S. Genetics Risk Factors for Musculoskeletal Soft Tissue Injuries. Med Sport Sci. 2009; 54: 136-49.

18. Posthumus M, September AV, Keegan M, O'Cuinneagain D, Van Der Merwe W, Schwellnus MP, Collins M. Genetic risk factors for anterior cruciate ligament ruptures: COL1A1 gene variant. Br J Sports Med. 2009; 43(5): 352-6.

19. Kruk J. Good scientific practice and ethical principles in scientific research and higher education. Cent Eur J Sport Sci Med. 2013; 1(1): 25-29.

20. September AV, Cook J, Handley CJ, Van Der Merwe L, Schwellnus MP, Collins M. Variants within the COL5A1 gene are associated with Achilles tendinopathy in two populations. Br J Sports Med. 43, 357-365, 2009.

21. Collins M, Posthumus M, Schwellnus MP, The COL1A1 gene and acute soft tissue. Ruptures. Br J Sports. 2009; 44: 1063-1064.

22. Hewett TE. Prevention of non-contact ACL injuries in Women: Use of the core of evidence to clip the wings of a "Black Swan". Curr Sports Med Rep. 2009; 8: 219-21.

23. Flyn RK, Pedersen CL, Birmingham TB, Kirkley A, Jackowski D, Fowler PJ. The familial predisposition toward tearing the anterior cruciate ligament: a case control study. Am J Sports Med. 2005; 33: 23-8.

24. Sawczuk M, Maciejewska A, Cięszczyk P, Eider J. The Role of genetic research in sport. Science\&Sports. 2011; 26: 251-8.

25. Mokone GG, Schwellnus MP, Noakes TD, Collins M. The COL5A1 gene and Achilles tendon pathology. Scand J Med Sci Sports. 2006; 16: 19-26.

26. Laguette MJ, Abrahams Y, Prince S, Collins M. Sequence variants within the 3'-UTR of the COL5A1 gene alters mRNA stability: Implications for musculoskeletal soft tissue injuries. Matrix Biology 2011; 30: 338-45.

27. Malila S, Yuktanandana P, Saowaprut S, Jiamjarasrangsi W, Honsawek S. Association between matrix metalloproteinase-3 polymorphism and anterior cruciate ligament ruptures. Genet Mol Res. 2011; 10: 4158-65.

28. Horn SD. Goodness-of-fit tests for discrete data: a review and an application to a health impairment scale. Biometrics. 1977; 33: 237-47.

29. Khoshnau S, Melhus H, Jacobson A, Rahme H, Bengtsson H, Ribom E, Grundberg E, Mallmin H, Michaëlsson K. Type I collagen alpha1 Sp1 polymorphism and the risk of cruciate ligament ruptures or shoulder dislocations. Am J Sports Med. 2008; 36: 2432-6.

30. Collins M, Posthumus M, Schwellnus M. The COL1A1 gene and acute soft tissue ruptures. Br J Sports Med. 2010; 44: 1063-4.

31. Posthumus M, September AV, O'cuinneagain D, Van Der Merwe W, Schwellnus MP, Collins M. The COL5A1 gene is associated with increased risk of anterior cruciate ligament ruptures in females. Am J Sports Med. 2009; 37: 2234-2240.

32. September AV, Posthumus M, Van Der Ml, Schwellnus M, Noakes TD, Collins M. The COL12A1 and COL14A1 genes and Achilles tendon injuries. Int J Sports Med. 2008; 29: 257-263. 